\title{
TENDENCY TO USE THE VIRTUAL FITTING ROOM IN GENERATION Y - RESULTS OF QUALITATIVE STUDY
}

\author{
Miroslaw MOROZ \\ Wroclaw University of Economics, Wroclaw, POLAND \\ e-mail: miroslaw.moroz@ue.wroc.pl
}

\begin{abstract}
E-commerce is growing rapidly on a global scale. Among many products purchased via the Internet, clothing is the first in terms of purchase frequency. However, there are growth barriers for this product category, which include, first of all, the client's fear of matching clothing to their own figure or complexion. This results in a high percentage of returns reaching up to $60 \%$ of transactions, which is more than that in other e-commerce sectors. One of the possible solutions to the abovementioned problem is the use of a virtual fitting room (VFR), which allows you to try on clothes in terms of size, fit, style, or color on a computer or smartphone screen. The main purpose of the article is to determine the propensity to use a VFR in the age group of generation Y. The second goal is to compare the propensity to use by type of VFR: 2D vs. 3D. The methodology is based on the qualitative exploratory approach. To conduct research, content analysis and sentiment analysis were used. The results of the study indicate that the participants of the research have an ambivalent attitude towards VFR - on the one hand, they perceive VFRs as an interesting solution for Internet users (not only generation Y). On the other hand, however, they themselves show a distance to use the VFR. The analysis also showed that a two-dimensional type of VFR based on augmented reality technology has greater market opportunities.
\end{abstract}

Keywords: virtual fitting room, virtual dressing room, virtual changing room, e-commerce, clothing industry, generation $\mathrm{Y}$, augmented reality, 3D mapping, human-computer interaction.

JEL: L81, M21, O33.

\section{$1 \quad$ Introduction}

E-commerce, understood as the sale of products and services via the Internet, records further records. Globally, the value of goods and services sold online increased from USD 1,336 trillion in 2014 to USD 2,842 trillion in 2018 (Statista, 2019a). The constant expansion of e-commerce is also confirmed by the growing share of online sales in relation to total sales (online and offline). In 2017, the share of online sales amounted to $10.2 \%$ of total global sales and increased from 7.4\% in 2 years (Bakopoulos, 2019). The reasons for this are many and varied, but, undoubtedly, the success of e-commerce was caused by the tendency to buy clothing manifested by Internet users.

Statistics show that clothing is the most popular online category worldwide, generating significant revenue volumes (Statista, 2019b). Certain features of clothing as a product category predestine it for online shopping. It is about a large selection (width and depth of the assortment), easy comparison of many sellers' offers, speed of changing the offer in response to changing fashion (including promotions), and convenience of shopping.

On the other hand, there are specific barriers, which include, first and foremost, the customer's fear of adjusting the clothing to their own figure or complexion and the inability to touch the material when selling at a distance. This results in a high return rate compared to other e-commerce sectors. The percentage of returns reaches up to $60 \%$ of transactions, so this is a real practical problem for e-sellers. One of the possible solutions is the use of a virtual fitting room (hereinafter VFR). The VFR allows anybody to virtually try on clothes in terms of size, fit, style, and color. The e-customer sees what it would look like in a given product. VFR essentially fulfills the function of a "virtual mirror" that allows to make a more conscious purchasing decision.

The research problem addressed in this article is the tendency of generation $Y$ to use VFRs in their shopping choices. VFR is a relatively new solution not 
implemented by online stores on a large scale. Therefore, VFR is not generally known to Internet users, including those from generation $\mathrm{Y}$, who are proficient in using information and communication technologies. Therefore, in order to determine the tendency to use VFR, it is necessary to conduct exploratory research that will give an in-depth picture of the attitude toward and willingness to use this type of application. In the study, two main types of VFR were taken into account: imitation of clothing on a two-dimensional likeness/photograph of a customer (the so-called 2D overlay) and imitation of clothing on a three-dimensional form, having the size of a customer (the so-called 3D mannequin). Research is geared toward two related objectives:

a) determining the propensity to use the VFR in the age group of generation $\mathrm{Y}$;

b) a comparison of the tendency to use by the type of VFR: 2D overlay vs. 3D mannequin.

\section{The essence and considerations of online sales of clothing}

E-commerce has become a permanent part of the economic landscape. Every day millions of customers shop online and see the following advantages (Turban, et al., 2018, p.16; Gemius, 2019, p.80):

- a wide range of products,

- possibility to immediately check the availability of the product,
- convenience of purchase,

- purchases 24 hours a day,

- possibility of self-configuration of the product,

- reduction of transaction costs,

- the opportunity to find an opportunity,

- right to a refund without giving reasons (on the European market),

- the various forms of payment available,

- easy product comparison.

The advantages correspond to the disadvantages of online shopping, which may include (Franco and Regi, 2016, pp.9-10; Gemius, 2019, pp.11-12):

- concerns about data security and payment security,

- privacy,

- occasional exceeding of the delivery time beyond the seller's declaration,

- relatively high delivery costs,

- no face-to-face interaction with the sales person,

- inability to see and touch the product.

In the opinion of online shoppers, the advantages far outweigh the disadvantages. As a result, the value of e-commerce turnover is higher year on year.

Table 1 shows the turnover generated by retail ecommerce worldwide and in Europe.

Table 1. E-commerce turnover worldwide and in Europe, from 2014 to 2019

(Source: own elaboration based on (Statista, 2019a; Ecommercenews, 2019)

\begin{tabular}{|l|c|c|c|c|}
\hline \multicolumn{1}{|c|}{ Year } & \multicolumn{2}{|c|}{ World } & \multicolumn{2}{c|}{ Europe } \\
\hline & $\begin{array}{c}\text { Turnover } \\
\text { (in billions USD) }\end{array}$ & Change & $\begin{array}{c}\text { Turnover } \\
\text { (in billions Euro) }\end{array}$ & Change \\
\hline 2014 & 1,336 & NA & 328 & NA \\
\hline 2015 & 1,548 & $15.87 \%$ & 386 & $17.68 \%$ \\
\hline 2016 & 1,845 & $19.19 \%$ & 429 & $11.14 \%$ \\
\hline 2017 & 2,304 & $24.88 \%$ & 489 & $13.99 \%$ \\
\hline 2018 & $2,842 \mathrm{E}$ & $23.35 \%$ & 547 & $11.86 \%$ \\
\hline 2019 & $3,453 \mathrm{E}$ & $21.50 \%$ & $621 \mathrm{E}$ & $13.53 \%$ \\
\hline Key: $\mathrm{E}-$ estimated; NA - not available & \\
\hline
\end{tabular}


The data quoted above indicate a dynamic increase in the scale of e-commerce turnover. Over the past 5 years, not a single year has been recorded with negative dynamics; on the contrary, the volume of turnover is increasing at a double-digit rate. Europe as a mature market has a slightly lower growth rate in relation to the globe, which is due to the greater dynamics of emerging markets.
The abovementioned advantage of e-commerce is the availability of many product categories. Clothing comes first in terms of purchase frequency (Nielsen, 2018; Eurostat, 2018). The online clothing sales segment is already generating significant revenues; forecasts for the future are equally optimistic.

Table 2 presents the value of the discussed ecommerce segment together with the forecast for 2021.

Table 2. Forecasts of number of customers and turnover for clothing segment of e-commerce in the United States and Europe (Source: Cullinane, et al., 2019, p.302)

\begin{tabular}{|c|c|c|c|c|c|c|}
\hline & \multicolumn{3}{|c|}{ United States } & \multicolumn{3}{c|}{ Europe } \\
\hline & 2016 & 2021 & CAGR & 2016 & 2021 & CAGR \\
\hline $\begin{array}{c}\text { E-shoppers } \\
\text { (millions) }\end{array}$ & 126 & $171 \mathrm{E}$ & $6.3 \%$ & 171 & $239 \mathrm{E}$ & $7 \%$ \\
\hline $\begin{array}{c}\text { Turnover } \\
\text { (millions USD) }\end{array}$ & 44,897 & $70,906 \mathrm{E}$ & $9.6 \%$ & 54,874 & $90,594 \mathrm{E}$ & $10.5 \%$ \\
\hline
\end{tabular}

Key: E - estimated; CAGR - compound annual growth rate

From the point of view of buyers, clothing purchases on the Internet enable the following benefits to be realized:

- wide choice of assortment, resulting from access to many sellers absent from the local market,

- speed of reaction of online sellers to seasonal changes, fashion factor,

- promotions and sales,

- convenient selection and ordering in the comfort of your own home,

- easy to compare the offers of many sellers,

- possibility to return without giving reasons (in most markets).

On the other hand, shopping at a distance is not so obvious. First of all, buying online does not allow you to try on a particular piece of clothing. And this is the basic criterion for choosing for this product category. A buyer in a traditional shop assesses the fit of a product, assesses color matching, and compares sizes (Pantano, et al. 2016, p.78). In the eshop, the customer does not have such a possibility, and yet she or he wants to look fashionable and attractive. Second, shopping at a distance involves the inability to touch the material from which the garment is made (Gao, et al., 2014, p.308).

Because of these two factors, the sales of clothing via the Internet are exposed to a large volume of returns (de Leeuw, et al., 2016, p.710; Patodiya and Birla, 2017, p.198). In addition, there is a change in buying behavior, leading to an additional increase in returns. More and more purchases are made on mobile devices, that is, spontaneously, without thinking about it - which generates additional streams of returned clothing (Clancy, 2016).

Another thing are people who intentionally order more pieces of clothing (e.g., in several close sizes), with a view to giving the least matching products. In the jargon of sellers, this type of customers is called "serial returners" and they constitute about $30 \%$ of buyers (Barclaycard, 2019). This category also includes people whose goal is to photograph themselves in new clothing and upload them to social networking sites (Barclaycard, 2019). These behaviors are called "snap and send back" or "hashtag moment."

The scale of returns made by customers varies depending on the situation (sex, clothing, and country) and ranges from $12 \%$ to $70 \%$ of transactions. "In the 
UK, the long-term return rate for clothing purchased online is $23 \%$ (...), in the US it is around $40 \%$ and in Germany (where until 2014 free returns were a legal right) it is 70\%" (Cullinane, et al., 2019, p.9). In Poland, in 2017, 12\% of clothing buyers returned it (Duszczyk, 2019). What's more, current trends indicate that the scale of returns will grow (DPD 2018).

Returns sent to such extent have consequences for the e-store in the financial, organizational, and human aspects. The process of accepting returns consists of four stages: developing a return policy, implementing return logistics, assessing the condition of the product returned by the customer, and accepting for further sale as a fully fledged product (after refreshing) or other decisions (discount sale, utilization, etc.) (compare Daaboul, et al., 2014, p.3). As a consequence, the return process hampers the daily operational management of $57 \%$ of e-sellers, and $20 \%$ of online store owners increase product prices to compensate for the costs of the entire business process (Barclaycard, 2016). According to research by Pur, et al., lowering the scale of returns by $10 \%$ would increase the profitability of the e-store by more than $20 \%$ (Urbanke, et al., 2015, p.1).

At this point, the question arises why e-sellers allow customers on such a scale of returns? There are two reasons for this. First of all, legal provisions protecting the interests of consumers guarantee that customers can return products without giving reasons (with the exceptions listed). Second, this is for competitive reasons. Liberal returns policy attracts customers. Hassle-free returns increase the confidence in the store and contribute to increased customer loyalty (Narvar, 2017).

In view of the above, e-tailers are carrying out various types of activities aimed at reducing the costs and effort associated with the product return process. The list of such activities includes better labeling or description of products, placing exact size tables, and launching stationary points (the so-called showroom). Some businesses have made a convenient reimbursement policy a basic instrument of competitive struggle. Zalando, one of the largest online clothing retailers, has offered a completely free product return and has extended the return period to 100 days. Another idea is to integrate VFRs with shop software, which would avoid the main reason for returns - a mismatch of a given piece of clothing to the actual size of customer body.

\section{$3 \quad$ Idea and types of the virtual fitting rooms}

The task of the VFR is to maximize the correct representation of the appearance and adjustment of a given item of clothing to the figure, skin complexion, and preferences of the customer on the screen of a computer or smartphone. In essence, VFRs are specially designed IT applications that allow for the superimposition of the modeled clothing on the customer's figure (Bazaki and Wanick, 2019, p.2). Therefore, two types of variables are needed: information about the size of the customer's body (height, neck, bust, waist, hips, and arm measurements) and information about the size of the selected piece of clothing, which should take into account, in addition to the abovementioned sizes, the degree of elasticity of the material from which the clothing is made. However, the mechanism of adjusting the garment to the client's figure will be different depending on whether we are dealing with $2 \mathrm{D}$ or $3 \mathrm{D}$ modeling.

The number of mapping dimensions is the main criterion for dividing VFRs. Two-dimensional VFR are based on augmented reality (AR) solutions. The AR enables images from the real world to be combined with computer-generated images, just like embedded artificial images in real range (Spreer and Kallweit, 2014, p.20). In order for AR solutions to work properly, a webcam is required to obtain real-world data. Since the beginning of the 21st century, advanced research on the use of $\mathrm{AR}$ for sales has been conducted (Bonetti, et al., 2018, p.119). One of the possible solutions in this respect are two-dimensional VFRs. Fig. 1 shows an example of a twodimensional VFR (also referred to as a 2D overlay in the text). 


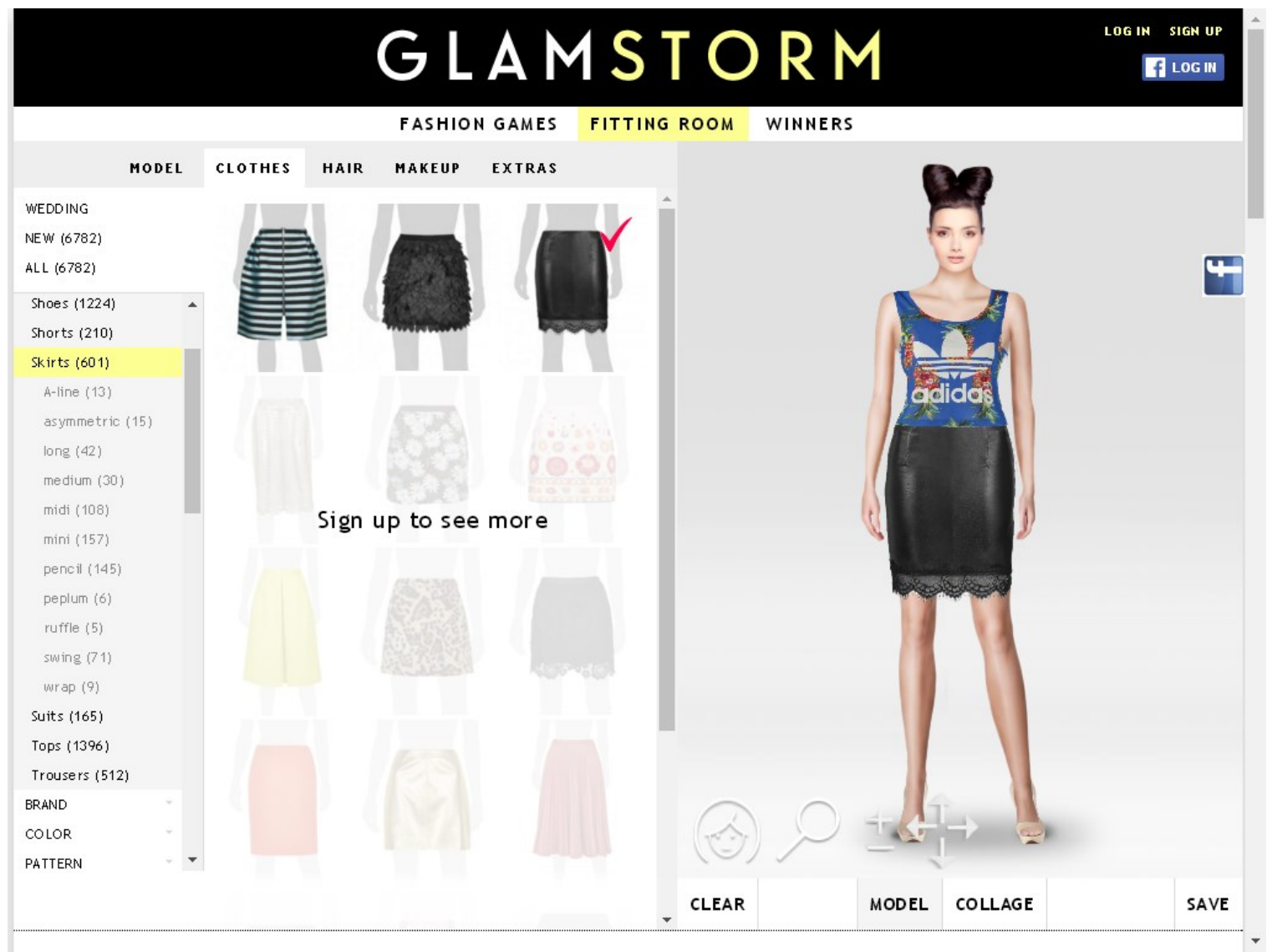

Figure 1. Example of a two-dimensional virtual fitting room (2D overlay VFR) (Source: Glamstorm, 2019)

Fig. 1 shows the essence of this type of VFR. On the real silhouette of the client and the real face (obtained through the camera), computer-generated and algorithmically fitted clothing elements are superimposed. After putting on the garment, the customer can see what she/he looks like in the garment. The generated image can be zoomed in and out, but not rotated, as the image has two dimensions.

The second main type of VFR is based on three dimensions. Next to the width and height, the depth appears, which allows user to rotate the body and see how the dress looks on the virtual avatars (mannequins). Such solutions are based on 3D modeling. In order for the application algorithm to create an avatar, it is necessary to enter body size data manually. This results in a personalized mannequin that can be viewed from different angles. Figs. 2 and 3 show an example of a three-dimensional VFR (also referred to as a $3 \mathrm{D}$ mannequin in the text).
After entering the body measurements, it is possible to model a selected item of clothing. The garment is presented on a mannequin; tight and loose places appear. You can easily fit on this one the optimal size of your clothes. You can not only zoom in and out of the garment but can also zoom in and out to view the garment from different angles. No skin or facial features are visible.

The VFR types discussed above do not exhaust all types of VFRs. The following approaches to the implementation of the VFR can still be found in the literature (Erra, et al., 2018, p.25078; West, 2017):

- size recommendation services,

- 3D body scanners,

- photo-accurate VFRs,

- virtual reality fitting rooms.

VFR variants, regardless of their differences and similarities, eventually fit into two mainstream VFRs $-2 \mathrm{D}$ or $3 \mathrm{D}$ mapping. 


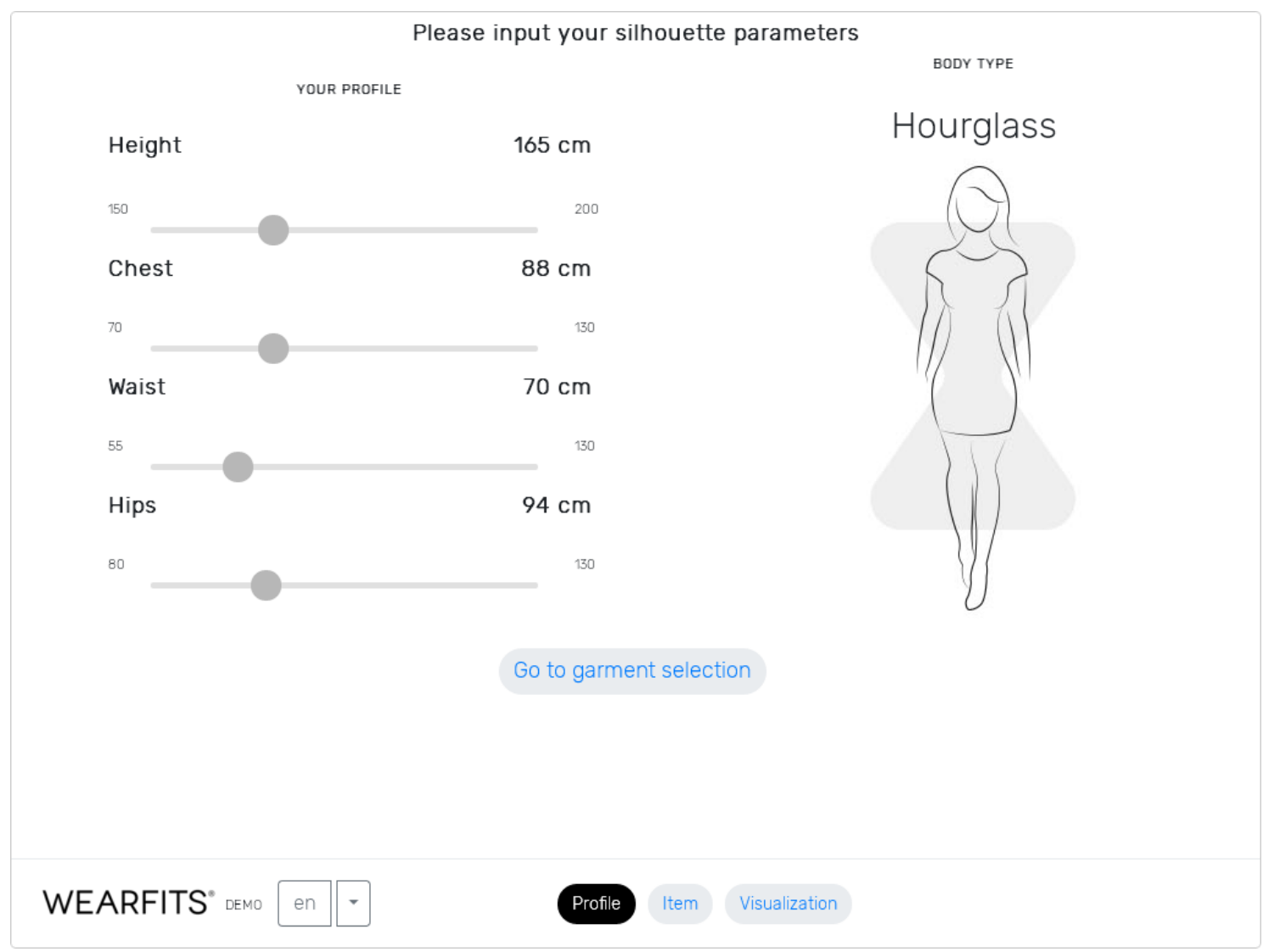

Figure 2. An example of a three-dimensional virtual fitting room (3D mannequin) - entering the size (Source: Wearfits, 2019)

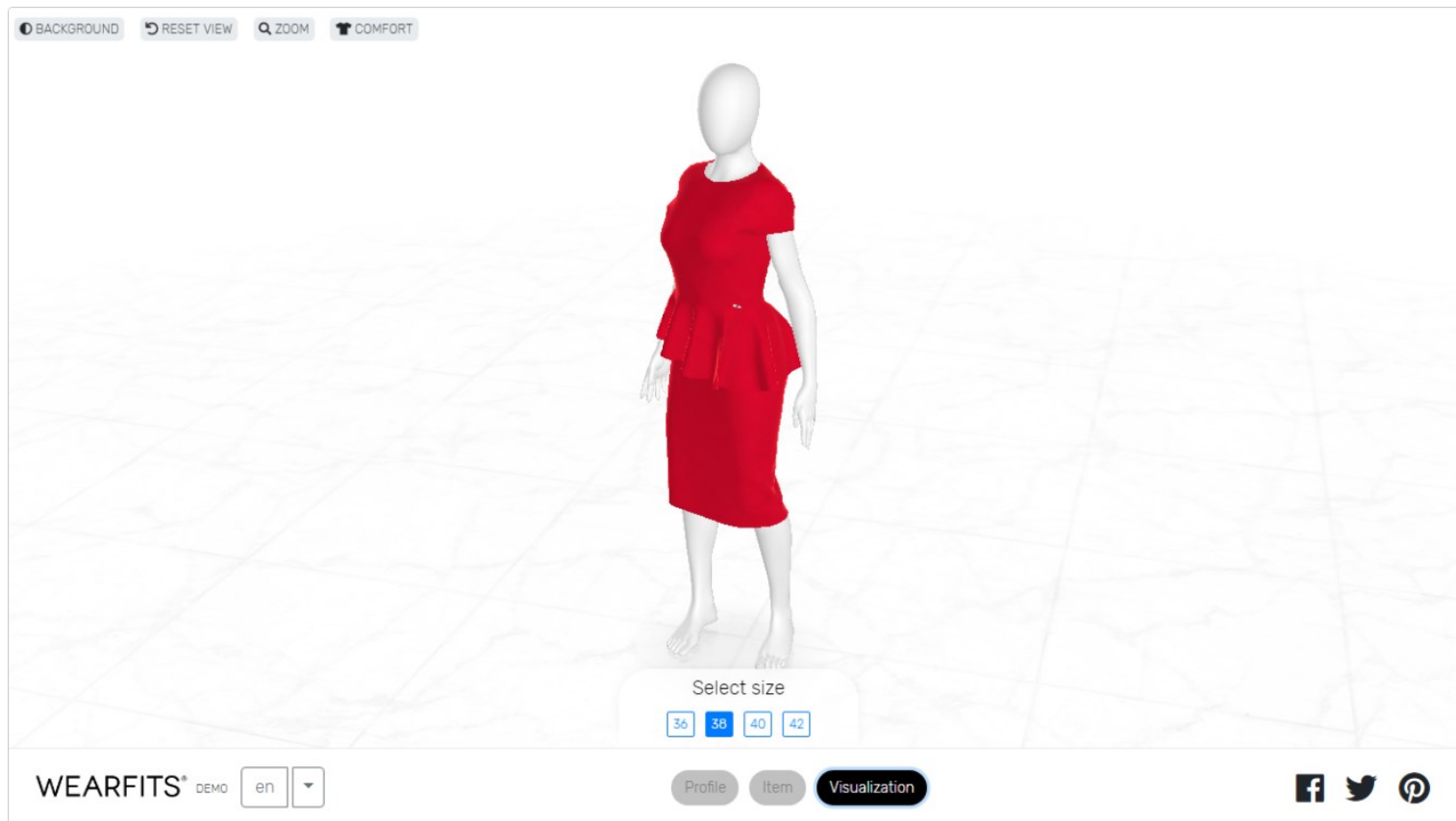

Figure 3. An example of a three-dimensional virtual fitting room (3D mannequin) - from visualization (Source: Wearfits, 2019) 
The literature is dominated by the view that the implementation of VFR has a positive impact on the eshop. First, the use of VFR contributes to reducing the number of customer returns. On the basis of the analysis of the global company ASOS, the author of the study found a $50 \%$ decrease in return shipments because of the use of two-dimensional VFR (Dunn, 2015).

Second, there is a positive relationship between the use of VFR and the purchasing decision approach (Patodiya and Birla, 2017, p.204). The authors found the above correlation based on a survey of 125 Indian respondents.

At the end of this section, it is worth noting that the development of useful VFR software is a complicated and complex task because of technical conditions: proper image capture (e.g., halftone reproduction), image transformation and adjustment, modeling the degree of material stiffness and motion, and so on (Boonbrahm, et al., 2015; Anagaha, et al., 2018).

\section{$4 \quad$ Research methodology}

The literature review as well as the author's own observations lead to the conclusion that there is a practical problem with a high percentage of returns in the online trade in clothing. One of the remedial methods aimed at reducing the rate of return of clothing are VFRs. However, the conducted search of literature revealed a small number of sources dealing with VFR issues from the client's perspective. As a result of a search of bibliographic databases and Internet resources, two studies were identified, studying the interest in using VFR by the client. The first one concerns key factors affecting consumer's acceptance of a real-time virtual fitting system. Surveys were conducted in Malaysia (Yen, et al., 2017, p.311). The second study was conducted in the United States and indicates that nearly $42 \%$ of the US e-customers are somewhat interested in using $\mathrm{AR} /$ virtual reality (VR) techniques while shopping (Koch, 2019). Therefore, in order to determine the tendency to use VFR, it is necessary to conduct further exploratory research that will give an in-depth picture of the attitude toward VFR and the willingness to use this type of application.
A research problem has emerged from the practical problem. The research problem addressed in this article is the tendency of generation Y to use VFRs in their shopping choices. VFR is a relatively new solution that is not implemented by online stores on a large scale. Therefore, VFR is not generally known to Internet users, including those of generation Y.

Generation $\mathrm{Y}$ is defined as persons born between 1981 and 1999 (Bolton, et al., 2013, p.255). The generation in question is proficient in Information and Communication Technologies (ICT). This is the basic feature that predestines this study. In addition, the generation $\mathrm{Y}$ has the highest tendency to file complaints compared to other generations (Soares, et al., 2017, p. 534). This can be a catalyst for online returns. Therefore, participants of the research were selected from this generation.

Two related objectives have been formulated. The main goal is to determine the tendency to use the VFR in the age group of generation Y. The secondary objective is to compare the tendency to use by the type of VFR: 2D overlay vs. 3D Mannequin.

Qualitative exploratory study design was adopted. Owing to the limited number of studies involving the willingness of customers to use VFR, in-depth qualitative studies are required. Qualitative research by its very nature helps to capture the whole context of a research problem. Qualitative research allows the participants to construct their statements freely, without rigidly sticking to the frames imposed by the questionnaire (Flick, 2018, pp.12-15). This is particularly valuable in exploratory research when cognition is at an early stage (Smith and Albaum, 2005, p.77). Second, qualitative research is indicated for those areas of research where there are research on intentions, motives, and beliefs (Hammersley and Atkinson, 1995, pp.27-29). This is related to the assumption that reality is an intersubjective human product by its subjective, diverse, and creative nature.

Qualitative research refers to many research techniques. Referring to the research problem and research goals, two qualitative research techniques were selected: content analysis (Duriau, et al., 2007) and sentiment analysis (Liu, 2012). 
The research procedure consists of three stages: collecting data, editing and organizing data, and conducting data analyzes.

Stage 1 consisted in familiarizing 23 people with the idea and types of VFR and identifying operating and publicly available VFR applications. On this basis, study participants play the role of VFR users. The user study was carried out at home, on personal computers, and on equipment of study participants. The testing conditions coincided completely with the standard VFR use. The subjects had a week to test two types of VFR in the pros and cons of both solutions and to determine the probability of using VFR. At the end, each participant prepared a comprehensive report in which he or she described his or her observations and conclusions freely. The user study was conducted in the fourth quarter of 2017.

Stage 2 consisted in editing and organizing reports. After analyzing the reports, it turned out that the observations and conclusions were repeated. Therefore, in accordance with the methodical recommen- dations, the number of reports was reduced to 7 (Eisenhardt, 1989, p.545). However, even this limited number of reports has produced extensive empirical material. Reports were selected according to the degree of saturation with different contexts of VFR use. To identify and encode the key concepts (nodes), Nvivo ver. 12 quality data analysis software was used.

Stage 3 consisted of analyzing structured data and drawing conclusions. This stage was carried out by means of content analysis, sentiment analysis, and cross query. The analyses were performed using Nvivo ver. 12 software.

\section{$5 \quad$ Findings of the study}

\subsection{Content analysis}

Seven reports prepared by study participants have provided extensive study data. Table 3 presents the numerical characteristics of the participants' statement.

Table 3. The research reports content summary

(Source: Own elaboration)

\begin{tabular}{|c|c|c|c|c|}
\hline Participant & $\begin{array}{c}\text { Total words } \\
\text { in file }\end{array}$ & $\begin{array}{c}\text { Total paragraphs } \\
\text { in file }\end{array}$ & $\begin{array}{c}\text { Number of nodes } \\
\text { coding file }\end{array}$ & $\begin{array}{c}\text { Number of text } \\
\text { references }\end{array}$ \\
\hline BARTHOLOMEW & 1,933 & 109 & 85 & 161 \\
\hline DAMIEN & 643 & 13 & 34 & 54 \\
\hline DOROTHY & 2,745 & 65 & 81 & 173 \\
\hline JOAN & 1,125 & 32 & 31 & 52 \\
\hline MARGARET & 1,491 & 47 & 44 & 65 \\
\hline MARK & 1,443 & 52 & 45 & 61 \\
\hline MARTINA & 1,681 & 19 & $222^{*}$ & 665 \\
\hline \multicolumn{7}{|c|}{ Total } & 11,061 & 337 & \\
\hline
\end{tabular}

The collected empirical material allowed to identify a total of 222 conceptual categories (nodes) associated with the use of VFR. In the statements of the respondents, 665 fragments (references) referring to the subject of the study were distinguished. Table 4 presents the terms that are most commonly used by survey participants to characterize VFR. 
Table 4. Word frequency query results (Source: Own elaboration)

\begin{tabular}{|c|c|c|c|}
\hline Word & Length & Count & Weighted Percentage (\%) \\
\hline Fitting & 7 & 97 & 1.7 \\
\hline Virtual & 7 & 89 & 1.56 \\
\hline Clothes & 7 & 87 & 1.52 \\
\hline Internet & 8 & 53 & 0.93 \\
\hline Online & 6 & 43 & 0.75 \\
\hline Product & 7 & 41 & 0.72 \\
\hline Overlay & 7 & 37 & 0.65 \\
\hline Clothing & 8 & 36 & 0.63 \\
\hline However & 7 & 29 & 0.51 \\
\hline Mannequin & 9 & 29 & 0.51 \\
\hline Website & 7 & 29 & 0.51 \\
\hline Application & 11 & 28 & 0.49 \\
\hline Dimensions & 10 & 27 & 0.47 \\
\hline Dressing & 8 & 27 & 0.47 \\
\hline Shopping & 8 & 27 & 0.47 \\
\hline Computer & 8 & 23 & 0.4 \\
\hline Customer & 8 & 23 & 0.4 \\
\hline Stores & 6 & 23 & 0.4 \\
\hline People & 6 & 22 & 0.39 \\
\hline Solution & 8 & 20 & 0.35 \\
\hline Trying & 6 & 20 & 0.35 \\
\hline Buying & 6 & 19 & 0.33 \\
\hline Camera & 6 & 19 & 0.33 \\
\hline Customers & 9 & 19 & 0.33 \\
\hline Changing & 8 & 17 & 0.3 \\
\hline
\end{tabular}

The most common words used by members of generation $\mathrm{Y}$ when discussing the use of VFR include mainstream research terms (e.g., fitting, virtual, clothes, internet, online, and shopping). Study participants actually focus on the description of trying on clothes online. It is worth noting, however, that the term referring to two-dimensional VFR appears more often. This means that study participants referred more to this type of VFR than to the second type of VFR "3D mannequin". The high position of the word "however" $(0.51 \%$ coverage $)$ is also puzzling. This suggests seeing the advantages and also disadvantages (or vice versa) of the tested VFR.

One of the objectives of the study is to determine preferences for the type of VFR. In their reports, study participants repeatedly refer to the pros and cons of both types of VFR. Here are some examples of insights regarding the benefits of a "2D overlay":

- „The ability to assess whether we look good in a given garment by substituting your own photo." 
- „After the photo is obtained, it is possible to download it to a computer disk or send it to Facebook or email. You can also save the clothing in the shopping basket or retake the photo if necessary."

- „Getting premium brands to a wider group of potential buyers - usually manufacturers of luxury, niche brands do not have a wide distribution network in traditional outlets."

- „The possibility of trying on a large number of clothes, which is often limited in traditional stores (three to five items can be taken on an average for the dressing room)."

- „It is possible to purchase the tried-and-tested clothes in an online store, which usually has more choice and availability of the range than in traditional stores."

- „The futuristic character can also be considered a significant advantage of the $2 \mathrm{D}$ overlay dressing room. The use of AR technology is quite a novelty on the Polish market."

The advantages of a 2D overlay are perceived by the subjects in relation to a specific reference point. This type of VFR is better compared to traditional fitting rooms (no limits on the number of clothes to be tried on), shops (wider choice), and novelty aspect (futuristic character). Ease of use and good mapping of clothing put on the tester's figure were also appreciated. The advantages of "2D overlays" correspond to the advantages. In the opinion of the study participants,

- „To use a 2D overlay, the client must have an Internet camera and access to the printer. In addition, a fast connection to the Internet is required, otherwise the use of the fitting room may be quite tedious (the motion detector reacts with a delay, the picture jams). What's more, the use of the "try on" option required to create the appropriate space (at least $1.5 \mathrm{~m}$ from the webcam) and background, as well as appropriate lighting. The biggest shortcomings also include the impossibility to adjust the size. Product images are simply applied to the webcam image."

- „The website itself has the option of taking pictures (which can then be downloaded), which means that they are saved on the servers. What's more, photos can be made automatically, even without the user's knowledge. The customer can, therefore, have an uncomfortable feeling that he or she is facing a Venetian mirror."

- „The problem is that the camera does not always read the code and does not want to activate, and even if it happens, it is quite difficult is to match the clothes to your figure, and the difficulties are set the right angle of the camera, the distance from the webcam and its quality, light, and background."

- „The inability to assess the quality, the cut, and how the product will fit our figure, and these are important aspects that are assessed when trying on the clothes and the decision whether to buy it."

- „The range of clothes to be fitted is very stingy, especially in the section intended for men."

- „This dressing room does not take into account the dimensions of our body, we cannot say what size will be suitable for us; therefore, the final effect does not impress, because it is simply "glued" element to our body."

Study participants raised many reservations about this type of VFR. In their opinion, the disadvantages relate primarily to an overly complicated method of operation, requiring precise positioning of a human, a computer, and a camera; not exactly matching the mapping of clothes to the client's figure; concerns about "leakage" of pictures taken while trying on; and a small selection of clothes for men modeled to $2 \mathrm{D}$.

In the subjects' opinion, the advantages of the "3D mannequin" solution are given as follows:

- „The VFR also positively surprises with intuitive design. First, after selecting the gender and type of clothes, the user should specify their dimensions covering basic categories such as height, chest circumference, waist circumference, or length of the body. With each category, you can display a hint on how to properly measure a given body part. The application then moves the user to preview the model with the previously indicated dimensions. From this level, you can change the size of clothes and watch changes online, the application suggests if the collar is too narrow or sleeves too long." 
- „In my opinion, the accuracy with which we can try on clothes is greater here than the 2D overlay because the actual dimensions are put on the clothes. The advantage here is that for a particular size it is shown how it will be laid on our body. Personally, I would be more willing to use this tool because it is more certain to me."

- „You can put on clothes and observe how the next sizes look like. Additionally, we can also see as the outfit looks from the back, it certainly makes it easier when the customer is not sure about his size of clothes."

- „In the case of this site, the plus I see is that we get information that, for example, the sleeve when choosing size L will be too short."

- „Possibility to use at any time, so there is no time limit as in traditional stores".

Study participants emphasize the intelligibility and ease of use of this type of VFR. The main advantage is hints on which size will be optimal for a person. It is also worth praising the opportunity to see how the clothing lies not only from the front (circular view) as well as unlimited trying on.

The defects of the "3D mannequin" solution were also pointed out:

- „All visualizations are indicated on a computer model, which users do not necessarily have to trust. Lack of self-preview in the attired clothes is the weaker point of the application."

- „I think, however, that it is not possible to check how a given cut or color suits us. In this respect, the virtual fitting room the $2 \mathrm{D}$ overlay is much more attractive to me."

- „What is particularly burdensome and to a large extent discourages the use of the "changing room," is the need to re-enter it on the occasion of any outfit that will interest us."

- „The amount of clothing possible to try on is very limited, and in principle only applies to the representative, for a given assortment group, models."

The main, repeated objection to the discussed type of VFR is the imperfect fitting of a given piece of clothing because of the lack of consideration of real facial features and skin complexion. This view is particularly articulated by women participating in the study. The second negative aspect is the relatively small assortment available, which can be visualized using this type of VFR. The problem comes from the fact that modeling every piece of clothing requires many hours of programmer's work and is time consuming.

The summary of the preference thread for the use of two types of VFR is the cross tabulation, presented in Table 5.

Table 5. Cross tabulation of advantages and disadvantages of VFR types - the number of references generated by study participants (Source: Own elaboration)

\begin{tabular}{|l|c|c|c|c|}
\hline & $\begin{array}{c}\text { Advantages } \\
\text { of 3D mannequin }\end{array}$ & $\begin{array}{c}\text { Advantages } \\
\text { of the 2D overlay }\end{array}$ & $\begin{array}{c}\text { Disadvantages } \\
\text { of 3D mannequin }\end{array}$ & $\begin{array}{c}\text { Disadvantages } \\
\text { of the 2D overlay }\end{array}$ \\
\hline BARTHOLOMEW & 8 & 5 & 1 & 4 \\
\hline DAMIEN & 2 & 2 & 1 & 2 \\
\hline DOROTHY & 8 & 6 & 1 & 9 \\
\hline JOAN & 2 & 4 & 2 & 5 \\
\hline MARGARET & 5 & 4 & 1 & 2 \\
\hline MARK Total & 28 & 1 & 23 & 14 \\
\hline MARTINA & 2 & 1 & 1 & 33 \\
\hline
\end{tabular}


Participants of the study at a similar level refer in their statements to the advantages of both "2D overlay" and "3D mannequin" (23 vs. 28 references). However, the opinion on the disadvantages of both types of VFR is different. It can be seen that the study participants experience the imperfections of the "2D overlay" much more often. However, the analysis of the content showed that the "3D mannequin" has one, but the main disadvantage is: it does not allow the VFR user to fully identify with the person visible on the screen. This in turn means that despite the fact that the participants in the study did not make too many criticisms of this type of VFR, the market success of the "3D mannequin" seems impossible.

In conclusion, both main types of VFRs have specific advantages and disadvantages. However, based on the analysis of the content, a two-dimensional VFR has greater market opportunities.

\subsection{Sentiment analysis}

People's statements are emotional. They reflect their attitude to a given phenomenon. This relationship can be positive, neutral, or negative. Semantic analysis of words and entire phraseological relationships can be carried out independently by the researcher or performed automatically by appropriate software. This study uses the latter method because the software used for qualitative data analysis has a sentiment analysis module (NVivo, 2019). Table 6 includes the number of references indicating a positive or negative attitude to the use of VFR by study participants.

Table 6. Cross tabulation of sentiment toward VFR - the number of references generated by study participants (Source: Own elaboration)

\begin{tabular}{|l|c|c|c|c|}
\hline & $\begin{array}{c}\text { Very } \\
\text { positive }\end{array}$ & $\begin{array}{c}\text { Moderately } \\
\text { positive }\end{array}$ & $\begin{array}{c}\text { Moderately } \\
\text { negative }\end{array}$ & $\begin{array}{c}\text { Very } \\
\text { negative }\end{array}$ \\
\hline BARTHOLOMEW & 2 & 9 & 10 & 5 \\
\hline DAMIEN & 3 & 1 & 2 & 3 \\
\hline DOROTHY & 7 & 16 & 15 & 1 \\
\hline JOAN & 3 & 9 & 7 & 3 \\
\hline MARGARET & 1 & 14 & 2 & 8 \\
\hline MARK & 9 & 13 & 5 & 4 \\
\hline MARTINA Total & 27 & 11 & 47 & 38 \\
\hline
\end{tabular}

The presented cross-section of sentiment analysis takes into account the gradation of the tone of the statement (very and moderately), while there is no neutral relation to the VFR. The total number of references with positive overtones reaches 100 references, while the negative attitude toward the use of VFR manifested itself 85 times. It can also be observed that a very positive or negative attitude occurs to a lesser extent than moderately marked statements about VFR (ratio such as 65:120).

More accurate data on sentiment are presented shown in Figure 4, showing in a slightly different cross-section the ratio of subjects to the use of VFR. The number of references indicating a positive, negative, neutral, or mixed attitude to the use of VFR was taken into account. A mixed response to VFR occurs when the same sentence contains both positive and negative sentiments (NVivo 2019).

Figure 4 contains two sections of research. The size of the field assigned to each research participant reflects the number of references generated by a given person. 


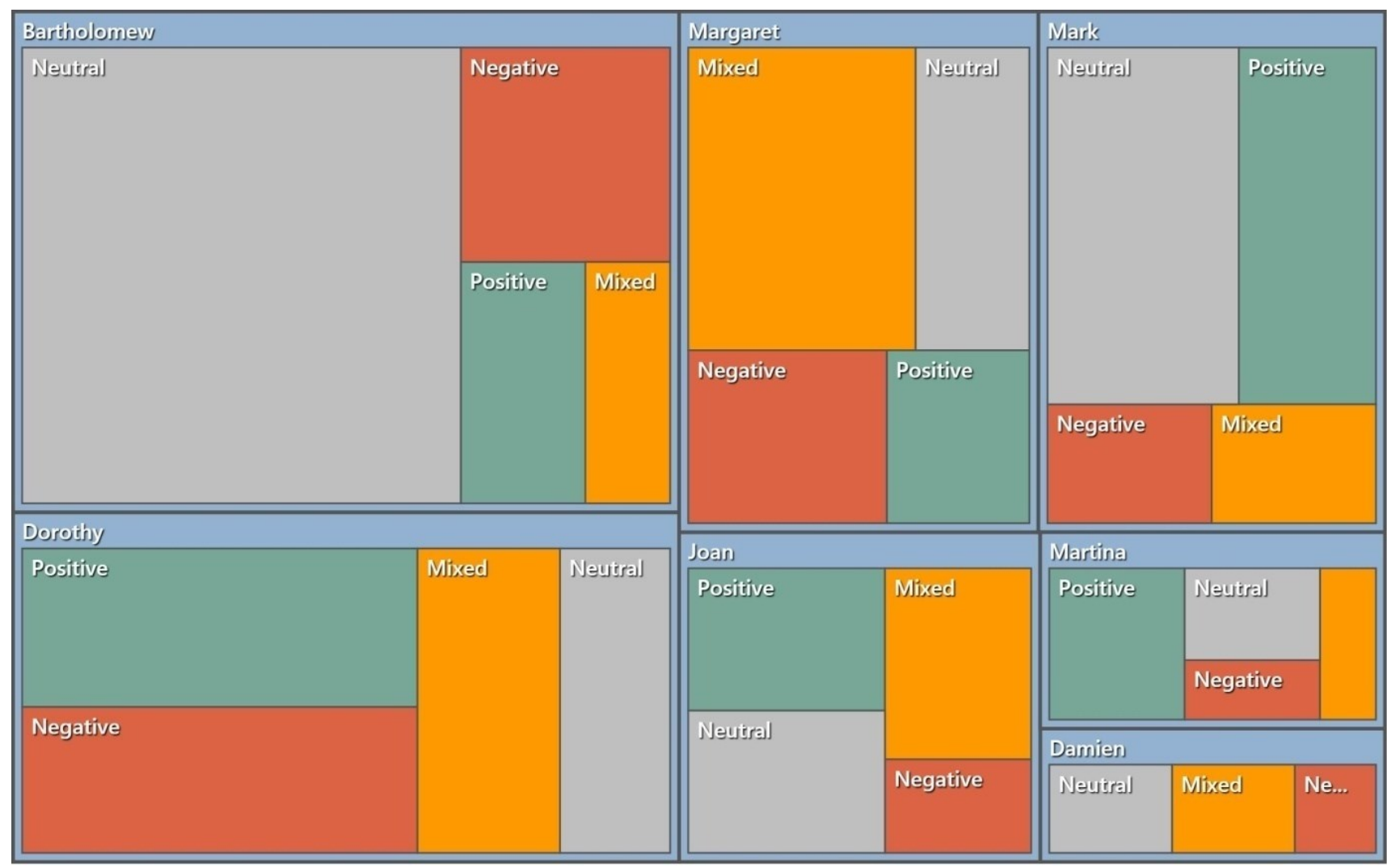

Figure 4. A sentiment chart resulting from the number of references generated by study participants (Source: Own elaboration based on NVivo ver. 12 software)

The sentiment for using the VFR includes four variants. An analysis of the drawing indicates that, only with respect to Martin and Dorothy, the positive VFR dominates. Damien, in turn, does not see any positive aspects of using VFR. Other people participating in the study are characterized by a neutral attitude to VFR (Bartholomew, Mark), mixed (Margaret), or balanced (as in Joan) attitude to VFR (roughly the same number of positive, negative, and mixed statements).

The predominance of mixed and neutral overtones in the references identified in the test participants' statements leads to the conclusion that the respondents are characterized by an ambivalent attitude to the idea of VFRs. So they see both the positive and negative aspects of using VFRs in a similar extent. They are not characterized by a clearly defined position toward the discussed solution.

\section{Conclusion}

Study participants have an ambivalent attitude toward using VFRs. On the one hand, they see VFRs as an interesting and desirable solution for people who want to buy clothing over the Internet. The subjects here pointed to the possibility of stress-free trying on clothes at home, at any time and place, without the looks of sellers or impatient accompanying people. They also emphasized the ease of use (although not in all aspects) and help in making purchasing decisions. On the other hand, they themselves showed a large distance to use the VFR. It is associated with the identified imperfections of each type of VFR. For "2D overlays," it is a relatively complicated method of service and "sticky" mapping of clothes on the form of the customer. For the "3D mannequin," it is a lack of consideration of facial features, the current hairstyle to match the outfit. The analysis of content as well as the analysis of sentiment shows that the tendency to use any of the types of VFR analyzed is neutral. The re- 
spondents treated VFRs more as a curiosity than a solution that generates added value.

The qualitative analysis showed that a twodimensional type of VFR has greater market opportunities. Although the "2D overlay" has accumulated a lot of negative references in the opinion of the participants, one feature is disqualifying for the second type of VFR. It is about the lack of realistic expression of facial features, complexion, shape, and color of the hairstyle. This is a disqualification factor for this type of VFR. Particularly from the perspective of the women participating in the study, the mentioned feature cancels the sense of using this type of VFR.

The subjects also raise the need to meet their requirements in terms of the full usability of available VFRs. Objectively speaking, the modeling of each item of clothing is time consuming and cost intensive. However, users demand fully functional software and do not accept any half measures or compromises to reflect their own appearance. This is also confirmed by existing studies (Huang and Liao, 2015, p.288). This means that further programming work is necessary to eliminate the perceived drawbacks. It is worth noting that many project teams are working on launching new versions of VFRs. For example, work is underway on the VFR that will be modeled in 3D and the virtual image will include the client's face (also in three dimensions) (Duszczyk, 2019).

The conducted qualitative analysis showed its advantages, identifying and revealing the context of the application conditions and market opportunities of VFR. However, this study is not free from limitations. The first is a relatively small number of study participants. By their very nature, qualitative research is not directed at the research of many participants, focusing on the context of cognition. However, the principle of triangulation requires quantitative research based on generated nodes. Second, the research took place in Poland. Performing the study in another country would increase the validity of conclusions and the objectivity of research. Third, with reference to one of the qualitative methods, grounded theory methods, it would be worth conducting a systematic study of the tendency to use VFRs spread over time.

\section{$7 \quad$ References}

[1] Anagaha, R., Brinda, D., Ankit, R.K., Vaishnavi, S., 2018. 3D Virtual Trial Room. In: NCESC 2018 Conference Proceedings. [online] Available at: https://www.ijert.org/research/3d-virtualtrial-room-IJERTCONV6IS13159.pdf [Accessed 15 August 2019].

[2] Bakopoulos, K., 2019. e-Commerce Share of Total Global Retail Sales from 2015 to 2021. [online] Available at: https://www.protocol. gr/2019/05/19/e-commerce-share-of-total-global -retail-sales-from-2015-to-2021/ [Accessed 15 August 2019].

[3] Barclaycard, 2016. Emergence of 'serial returners' - online shoppers who habitually over order and take advantage of free returns - hinders growth of UK businesses [online] Available at: https://www.home.barclaycard/media-centre/pre ss-releases/emergence-of-serial-returners-hinder s-growth-of-UK-businesses.html [Accessed 15 August 2019].

[4] Barclaycard, 2019. The age of the 'serial returner'. [online] Available at: https://www.home. barclaycard/insights/payments/The-age-of-theserial-returner.html [Accessed 15 August 2019].

[5] Bazaki, E. Wanick, V., 2019. Unlocking the Potential of the Salesperson in the Virtual Fitting Room: Enhancing the Online Retail Experience for Fashion Brands. [online] Available at: https://eprints.soton.ac.uk/432242/1/3d_virtual_r oom_services_final_camera_ready_EB.pdf [Accessed 15 August 2019].

[6] Bolton, R.N., Parasuraman, A., Hoefnagels, A., Migchels, N., Kabadayi, S., Gruber, T., Komarova Loureiro, Y. and Solnet, D., 2013. Understanding Generation $\mathrm{Y}$ and their use of social media: a review and research agenda. Journal of Service Management, 24(3), pp.245-267.

[7] Bonetti, F., Warnaby, G. and Quinn, L., 2018. Augmented reality and virtual reality in physical and online retailing: A review, synthesis and research agenda. In: Augmented reality and virtual reality. Cham: Springer, pp.119-132.

[8] Boonbrahm, P., Kaewrat, C. and Boonbrahm, S., 2015. Realistic simulation in virtual fitting room using physical properties of fabrics. Procedia Computer Science, 75, pp.12-16. 
[9] Clancy, O., 2016. Most online clothes shoppers send something back. BBC. [online] Available at: https://www.bbc.com/news/business-363957 19 [Accessed 15 August 2019].

[10] Cullinane, S., Browne, M., Karlsson, E. and Wang, Y., 2019. Retail Clothing Returns: A Review of Key Issues. In: Contemporary Operations and Logistics. Cham: Palgrave Macmillan, pp.301-322.

[11] Daaboul, J., Le Duigou, J., Penciuc, D. and Eynard, B., 2014. Reverse logistics network design: a holistic life cycle approach. Journal of Remanufacturing, 4(1), pp.1-15.

[12] de Leeuw, S., Minguela-Rata, B., Sabet, E., Boter, J. and Sigurðardóttir, R., 2016. Trade-offs in managing commercial consumer returns for online apparel retail. International Journal of Operations \& Production Management, 36(6), pp.710-731.

[13] DPD, 2018. E-shopper barometer report 2018 [online] Available at: https://www.dpd.com/gro up/wp-content/uploads/sites/77/2019/03/201903 27_e-shopper_barometer_2018.pdf [Accessed 15 August 2019].

[14] Dunn, Ch. 2015. How Sizing Technology Can Bring Online Apparel Returns Down to Zero. [online] Available at: https://www.mytotalretail. com/article/sizing-technology-can-bring-onlineapparel-returns-zero/all/ [Accessed 15 August 2019].

[15] Duszczyk, M., 2019. Wirtualna przymierzalnia nadzieja e-sklepów (A virtual fitting room is the hope of e-shops). [online] Available at: https://cyfrowa.rp.pl/biznes/33935-wirtualna-prz ymierzalnia-nadzieja-e-sklepow [Accessed 15 August 2019].

[16] Duriau, V.J., Reger, R.K. and Pfarrer, M.D., 2007. A content analysis of the content analysis literature in organization studies: Research themes, data sources, and methodological refinements. Organizational research methods, 10(1), pp.5-34.

[17] Ecommercenews, 2019. The ecommerce market in Europe. [online] Available at: https://ecom mercenews.eu/ecommerce-in-europe/ [Accessed 15 August 2019].
[18] Eisenhardt, K.M. (1989), Building theories from case study research, Academic Management Review, 14 (4), pp.532 - 550.

[19] Erra, U., Scanniello, G. and Colonnese, V., 2018. Exploring the effectiveness of an augmented reality dressing room. Multimedia Tools and Applications, 77(19), pp.25077-25107.

[20] Eurostat, 2018. E-commerce statistics for individuals. [online] Available at: https://ec.europa. eu/eurostat/statistics-explained/pdfscache/46776. pdf [Accessed 15 August 2019].

[21] Flick U., 2018. Designing Qualitative Research. The Sage Qualitative Research Kit, 2nd edition. London: Sage.

[22] Franco, C.E. and Regi, B.S., 2016. Advantages and challenges of e-commerce customers and businesses: in Indian perspective. International Journal of Research - Granthaalayah,4(7), pp.7-13.

[23] Gao, Y., Brooks, E.P. and Brooks, A.L., 2014. The performance of self in the context of shopping in a virtual dressing room system. In: International Conference on HCI in Business. Cham: Springer, pp.307-315.

[24] Gemius, 2019. E-commerce w Polsce. Gemius dla e-Commerce Polska (E-commerce In Poland. Gemius for e-Commerce Poland). Warsaw. [online] Available at: https://www.gemius. pl/ecommerce2019/cac74bec2fac091ac0370e91 8bdf5e3e [Accessed 15 August 2019].

[25] Glamstorm, 2019. Fitting Room. [online] Available at: hhttp:/glamstorm.com/en/fittingroom/ clothes/c/skirts\#cat_4 [Accessed 15 August 2019].

[26] Hammersley, M., Atkinson, A ., 1995. Ethnography: Principles in Practice. Second edition. London: Routledge.

[27] Huang, T.L. and Liao, S., 2015. A model of acceptance of augmented-reality interactive technology: the moderating role of cognitive innovativeness. Electronic Commerce Research, 15(2), pp.269-295.

[28] Koch, L., 2019. Nike Unveils Nike Fit: Will AR Initiative Help Retailer Combat Returns, Drive Mobile Sales?. [online] Available at: https:// www.emarketer.com/content/nike-unveils-nike- 
fit-will-ar-initiative-help-retailer-combat-returns -drive-mobile-sales [Accessed 15 August 2019].

[29] Liu, B., 2012. Sentiment analysis and opinion mining. Synthesis lectures on human language technologies, San Rafael: Morgan \& Claypool Publishers.

[30] Narvar, 2017. Making Returns a Competitive Advantage [online] Available at: https://see. narvar.com/rs/249-TEC-877/images/Narvar_Con sumer_Survey_Returns_June2017.pdf [Accessed 15 August 2019].

[31] Nielsen, 2018. Top categories purchased online (\% of a global online consumers having purchased, 2018). [online] Available at: https:// www.marketingcharts.com/charts/top-5-popularcategories-purchased-online/attachment/nielsentop-categories-purchased-online-dec2018 [Accessed 15 August 2019].

[32] NVivo, 2019. Mixed sentiment coding. [online] Available at: https://help-nv.qsinternational. com/12/win/v12.1.86-d3ea61/Content/coding/au to-detect-code-sentiment.htm?Highlight=sentim ent [Accessed 15 August 2019].

[33] Pantano, E., Nguyen, B., Dennis, C. and Gerlach, S., 2016. Internet retailing and future perspectives. New York: Routledge.

[34] Patodiya, P.K. and Birla, P., 2017. Impact of Virtual-Try-On Online Apparel Shopping Decisions. Review Journal of Philosophy \& Social Science, Vol. 42, No.2, pp.197-206.

[35] Smith, S., M., Albaum, G.S., 2005. Fundamentals of marketing research. Thousand Oaks: SAGE Publications.

[36] Soares, R.R., Zhang, T.T., Proença, J.F. and Kandampully, J., 2017. Why are Generation Y consumers the most likely to complain and repurchase? Journal of Service Management, 28(3), pp.520-540.

[37] Spreer, P. and Kallweit, K., 2014. Augmented reality in retail: assessing the acceptance and potential for multimedia product presentation at the
PoS. Transactions on Marketing Research, 1(1), pp.20-35.

[38] Statista, 2019a. Retail e-commerce sales worldwide from 2014 to 2021 (in billion U.S. dollars). [online] Available at: https://www.statista.com /statistics/379046/worldwide-retail-e-commercesales/ [Accessed 15 August 2019].

[39] Statista, 2019b. Share of internet users who have purchased selected products online in the past 12 months as of 2018. [online] Available at: https://www.statista.com/statistics/276846/reach -of-top-online-retail-categories-worldwide/ [Accessed 15 August 2019].

[40] Turban, E., Outland, J., King, D., Lee, J.K., Liang, T.P. and Turban, D.C., 2017. Electronic commerce 2018: a managerial and social networks perspective. New York: Springer.

[41] Urbanke, P., Kranz, J. and Kolbe, L., 2015. Predicting product returns in e-commerce: the contribution of mahalanobis feature extraction. In: Thirty Sixth International Conference on Information Systems, Forth Worth. [online] Available at: https://www.researchgate.net/publication/283 271154_Predicting_Product_Returns_in_E-Co mmerce_The_Contribution_of_Mahalanobis_Fe ature_Extraction_Completed_Research_Paper/ci tation/download [Accessed 15 August 2019].

[42] Wearfits, 2019. Demo Fitting Room. [online] Available at: https://demo-new.wearfits.com/\# [Accessed 15 August 2019].

[43] West, P., 2017. Virtual Fitting Rooms With The HoloLens. [online] Available at: https:// vrscout.com/news/virtual-fashion-dressing-room -hololens/ [Accessed 15 August 2019].

[44] Yen, Y.Y., Narayanasamy, K., Lin, C.Y., Rasiah, D. and Ramasamy, S., 2017. Consumer's perception towards real-time virtual fitting system. In: Proceedings of the 6th International Conference on Computing and Informatics, Kuala Lumpur, University of Utara Malaysia, pp.311-316. 